\title{
WEAR BEHAVIOR OF WOVEN ROVING ARAMID / EPOXY COMPOSITE UNDER DIFFERENT CONDITIONS
}

\author{
Asad A. Khalid \\ Department of Mechanical Engineering, Faculty of Engineering, \\ International Islamic University Malaysia, Jalan Gombak, 53100 , Malaysia \\ e-mail:asad@iiu.edu.my
}

\begin{abstract}
Wear behavior studies of aramid woven roving /epoxy composite has been conducted. Sliding the material against smooth steel counter face under dry and lubricated with oil conditions has been investigated. Powder of Silicon carbide has been mixed with the epoxy resin and tested also. The powder was mixed in a volumetric fraction of $10 \%$ with the epoxy resin. Four Laminates of six layers were fabricated by hand lay up method. A pin on disc apparatus has been fabricated to conduct the sliding wear tests on specimens of $(4 \mathrm{~mm} \times 4 \mathrm{~mm} \times 12 \mathrm{~mm})$ in size have been cut from the four laminates. The effect of sliding condition including dry, lubricated, dry with additives and lubricated with additives have been studied. Wear rate tests have been conducted at different sliding speeds and loads. Results show that the wear characteristics are influenced by the operating conditions and the construction of the composite material used. It was also found that the wear of aramid lepoxy composite onto the steel counter face were significantly reduced by using lubricant and additives but still took place.
\end{abstract}

Keywords: Wear, Composite materials, Woven roving aramid, Epoxy, Additives, Lubricant.

\section{INTRODUCTION}

The continuing growth in the scope of applications of fiber reinforced composites in various industries has provided considerable incentive for the study of tribological aspects of composite behavior. Friction and wear resistance are not intrinsic material properties but are complex functions of a large number of external parameters (sliding velocity, normal load, environment, geometry, etc.) of the physical and mechanical properties of wearing and counterface materials.

Tribological studies on composite materials have focused attention on the effect of fiber type and orientation, load, matrix resin type, sliding speed, etc., on friction and wear behavior of composites [1-9]. Otherwise, the studies of friction and wear have focused on polymeric composites (unidirectional reinforcing fibers). Also, wear have been studied on fiber-reinforced composites of different matrix resins and fiber volume fraction sliding under dry conditions against a metallic counter face. Wear behavior of glass woven roving/ modified phenolic composites has been studied by Vishwanath et 
al. [5]. Theyconcluded that the volumetric wear rate increased non linearly with both the sliding velocity and normal load.

Aramid fibers have the lowest specific gravity and highest tensile strength to weight ratio but the lowest strength at high temperatures [10,11]. Among the current reinforcing fibers, aramid fibers and as reinforcement, are being used in many marine and aerospace applications and helmets. Where light-weight, high tensile strength, resistance to impact and better chemical and thermal stability is necessary. Besides that, aramid fibers become more and more important as structural materials. Thus, it is necessary to study and to improve its wear resistance.

Throughout this research, experimental wear tests have been carried out for woven roving aramid/epoxy composite. The volumetric wear rates were taken for dry, lubricated, dry with additive, and lubricated with additives specimens. Wear equipment (pin on disc apparatus) was fabricated to study the effect of different sliding conditions at different speeds and different loads.

\section{MATERIAL PROPERTIES}

\subsection{Woven roving Fiber and Matrix specification}

Laminates of aramid plain woven roving fabric shown in Fig. 1, were supplied by OCF Owens Corning (USA). Epoxy resin mixed with hardener in a volumetric ratio of 1:0.25 was used as a matrix material. The properties of the fiber and matrix used are shown in Table 1.

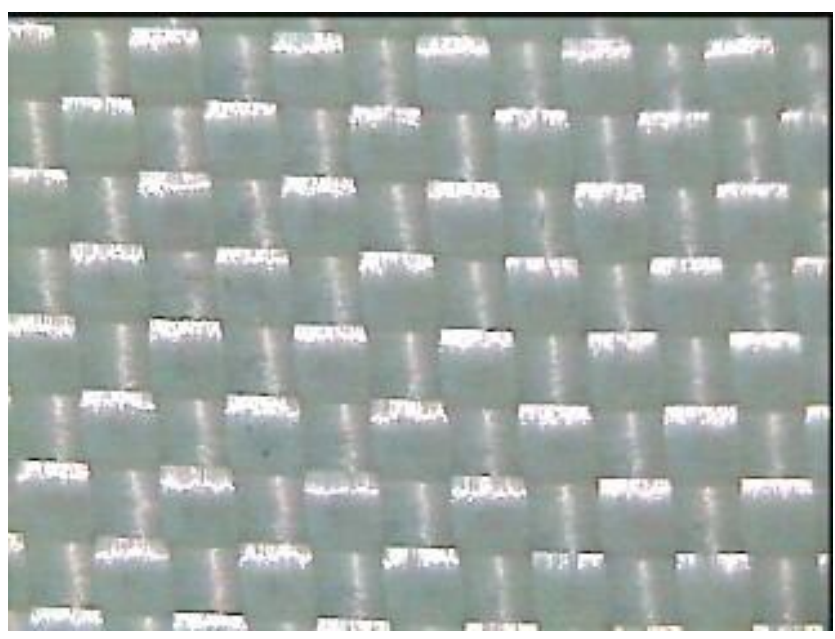

Fig. 1: Aramid fiber. 
Table 1 Properties of fiber and its matrix.

\begin{tabular}{|c|c|c|}
\hline Properties & Aramid fiber & $\begin{array}{c}\text { Matrix (Epoxy resin with } \\
\text { Hardener) }\end{array}$ \\
\hline Density, $\rho\left(\mathrm{g} / \mathrm{cm}^{3}\right)$ & $1.45 \mathrm{~g} / \mathrm{cm}^{3}$ & $1.14 \mathrm{~g} / \mathrm{cm}^{3}$ \\
\hline Ultimate Tensile Strength, $\sigma \mathrm{u}$ & $3.8 \mathrm{GN} / \mathrm{mm}^{2}$ & $0.07 \mathrm{GN} / \mathrm{mm}^{2}$ \\
\hline Modulus of Elasticity, E & $131 \mathrm{GN} / \mathrm{mm}^{2}$ & $7 \mathrm{GN} / \mathrm{mm}^{2}$ \\
\hline
\end{tabular}

\subsection{Composite Laminates}

The epoxy resin type LECO 811-164, and hardener type LECO 811-166 were used for this investigation. The aramid fiber volume fraction was 0.65 .

Woven roving aramid fiber with epoxy resin plies of $300 \mathrm{~mm}$ x $300 \mathrm{~mm}$ were fabricated by hand lay-up of six layers of aramid woven roving fabrics cured at a room temperature of $32^{\circ} \mathrm{C}$ for 24 hours. The resin was filled with $10 \%$ in volume of particles of Silicon carbide additive. Specimens of rectangular cross-section of $4 \mathrm{~mm} \times 4 \mathrm{~mm}$, and $20 \mathrm{~mm}$ length were cut from the composite laminates and used for the wear tests. The reinforcements placed in parallel with respect to the sliding plane. Samples of the fabricated specimens are shown in Fig. 2. The initial weight of the specimens were in the range of 10 to $10.45 \mathrm{~g}$. The properties of woven roving aramid/epoxy composite specimens are shown in Table 2.

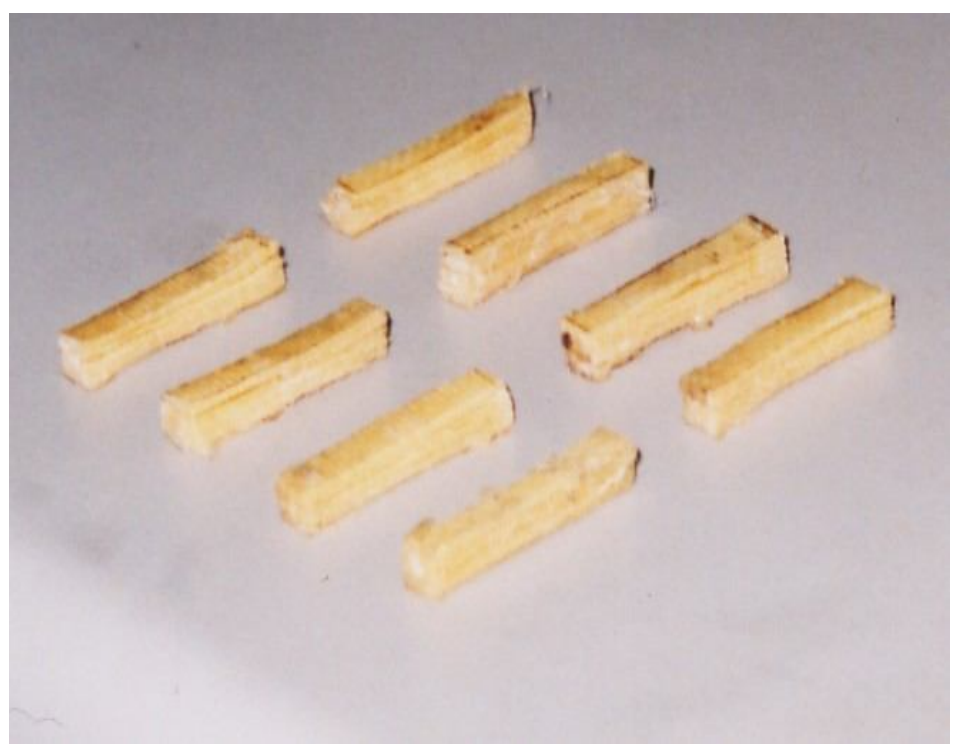

Fig. 2: Sample of woven roving aramid/epoxy composite specimens. 
Table 2: Properties of fiber and its matrix.

\begin{tabular}{|c|c|}
\hline Properties & Aramid/epoxy \\
\hline Density, $\rho\left(\mathrm{g} / \mathrm{cm}^{3}\right)$ & 1.44 \\
\hline Ultimate Tensile Strength, $\sigma_{u}\left(\mathrm{GN} / \mathrm{m}^{2}\right)$ & 1.38 \\
\hline Modulus of Elasticity, $\mathrm{E}_{11}, \mathrm{E}_{22}\left(\mathrm{GN} / \mathrm{m}^{2}\right)$ & 88 \\
\hline Poisson's Ratio, $v$ & 0.34 \\
\hline
\end{tabular}

\section{EXPERIMENTAL SET UP}

Pin on disc apparatus as shown in Figure 3, was designed and fabricated to carry out the sliding wear tests under dry and lubricated conditions. The schematic diagram of the pin on disc apparatus is shown in Fig. 4. As shown, the specimen (1) is mounted on an adjustable holder (2). Normal load on the specimen can be applied by placing dead weights (3) on the specimen holder (4). A horizontal holder (5) has the ability to extend and to move vertically on a vertical arm (6). A rubbing disc (7) is mounted on a shaft (8). The shaft is supported by two ball bearings. A V-belt (9) and two pulleys (10) were used to transfer the motion from an electric motor (11) to the shaft. The motor is connected to a speed controller to obtain different sliding velocities. A gear box (12) of speed ratio 1:10 is connected to the motor by a flexible coupling (13). For the purpose of lubricated wear tests, a lubricating system (14) is used. A steel table (15) is used to hold all the equipment of the wear testing.

A range of sliding velocities could also be obtained by varying the radial location of the specimen on the rubbing disc. The sliding experiments were carried out at a speed varied from $0.5 \mathrm{~m} / \mathrm{s}$ to $2 \mathrm{~m} / \mathrm{s}$ and the applied normal load was in the range from 2.5 to $10 \mathrm{~N}$.

A ground finished cast iron disc of surface roughness in the range of 0.14 to $0.15 \mathrm{~mm}$ (CLA) and hardness $180 \mathrm{HRB}$ was used as a counter face. The composite wear rate was determined by measuring the mass loss of the specimen at a steady state condition after every test run interval. The average of three repeated tests was taken for each time interval. Fabricated woven roving aramid/epoxy composite specimens have the crosssection $4 \mathrm{~mm} \times 4 \mathrm{~mm}$ and length $25 \mathrm{~mm}$. Each specimen was slid 30 minutes on a mild steel disc and the average of three repeated tests was taken for each specimen tested. The volumetric wear rate for each composite specimen was calculated for the duration of 30 minutes.

A lubricating oil (SAE 30) was used during the lubricated wear tests. While the silicon carbide was used as an additive mixed with the matrix in a volumetric fraction of $10 \%$. 


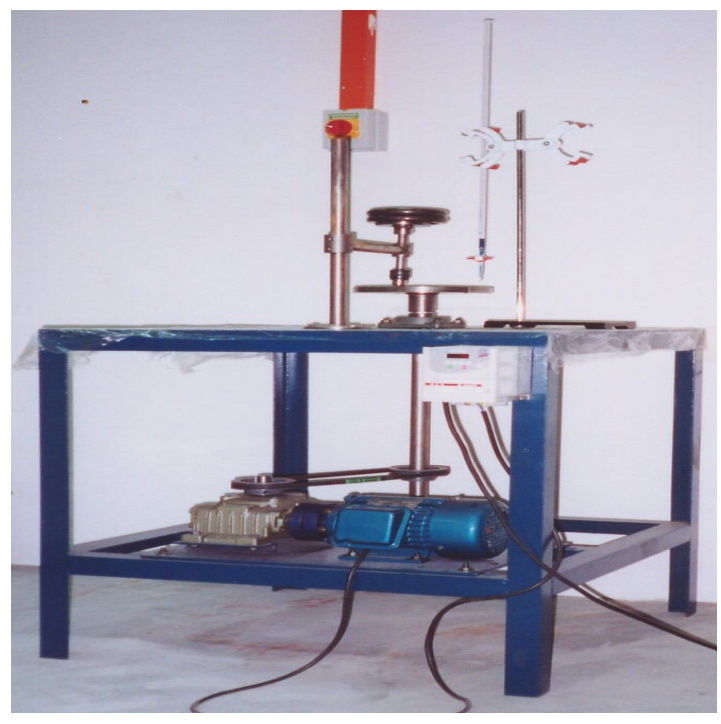

Fig. 3: Wear test rig.

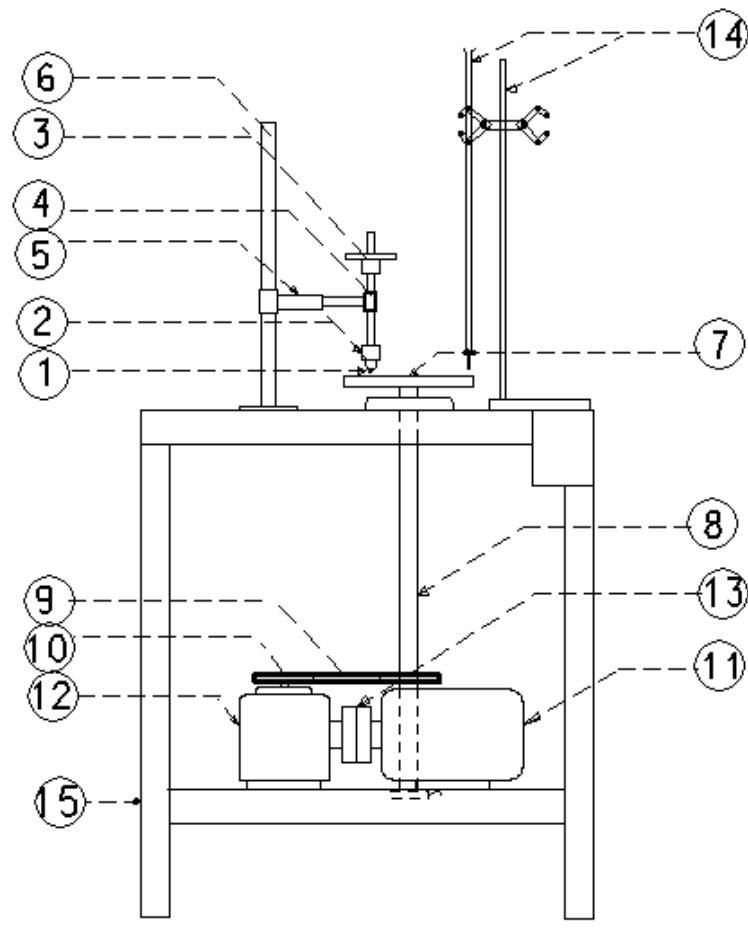

\begin{tabular}{|c|c|c|c|}
\hline to. & Port Hons & Nateriol & oty. \\
\hline I & Speciman & Armid $d \theta p d x y$ & 1 \\
\hline 2 & Adjustw le holdar & Stael & 1 \\
\hline 3 & heod neights & Stagl & 1 \\
\hline 4 & Spescinen hal der & Steal & 1 \\
\hline 5 & Hor izontal hol dar & Starl & 1 \\
\hline 5 & Yartlcal arm & Stäl & 1 \\
\hline 1 & Rabbling dlac & Steel & 1 \\
\hline B & Shaft & Staal & 1 \\
\hline 9 & Y-belt & El ostanar & 1 \\
\hline 10 & Pulley & - & 2 \\
\hline 11 & Elestris moter & - & 1 \\
\hline 12 & Gear box & - & 1 \\
\hline 13 & capl ing & Stael & 1 \\
\hline 14 & Lubrication Systam & - & 1 \\
\hline 15 & Tast Rig Empluosmant & Stęl & 1 \\
\hline
\end{tabular}

Fig. 4: Schematic diagram of pin on disc apparatus.

\section{RESULTS}

Results from this study include the effects of applied normal load, sliding velocity and wear test condition. Besides that, scanning electron micrographs of some selected specimens were taken for a comparison purpose. 
According to Visconti [3], the wear rate could be calculated by the following equation:

$$
W=\frac{\mathrm{D} m}{r \mathrm{~A} V_{S} t},
$$

where $\mathrm{D} m$ is the mass loss $(\mathrm{g}), r$ is the density $\left(\mathrm{g} / \mathrm{m}^{3}\right), A$ is the apparent area of surface contact $\left(\mathrm{m}^{2}\right), t$ is test time $(\mathrm{s})$, and $V_{S}$ is the sliding velocity $(\mathrm{m} / \mathrm{s})$.

Wear losses were determined by the weight-loss method. The weight loss was measured by using an electron balance. For different normal loads and sliding velocities, data for the wear rate of the composite were obtained. For each test, three types of laminates were examined. An average data of three tests was taken. The test time was 30 minutes and the weight loss measurements were made at 10 minutes intervals by electron balance. The diameter of path was $180 \mathrm{~mm}$.

\subsection{Sliding velocity}

Figures 5 to 8 show the effect of sliding velocity on the wear rate of woven roving aramid/epoxy composite specimens at different loads. As shown from these figures, the wear rate increases with increasing sliding velocity and will be increased at higher loads.

Dry, lubricated, dry with additives and lubricated with additives have been tested. The lowest wear rate of 17.5 was found in a lubricated composite specimens with additives at a sliding velocity of $2 \mathrm{~m} / \mathrm{s}$ and applied normal load of $10 \mathrm{~N}$.

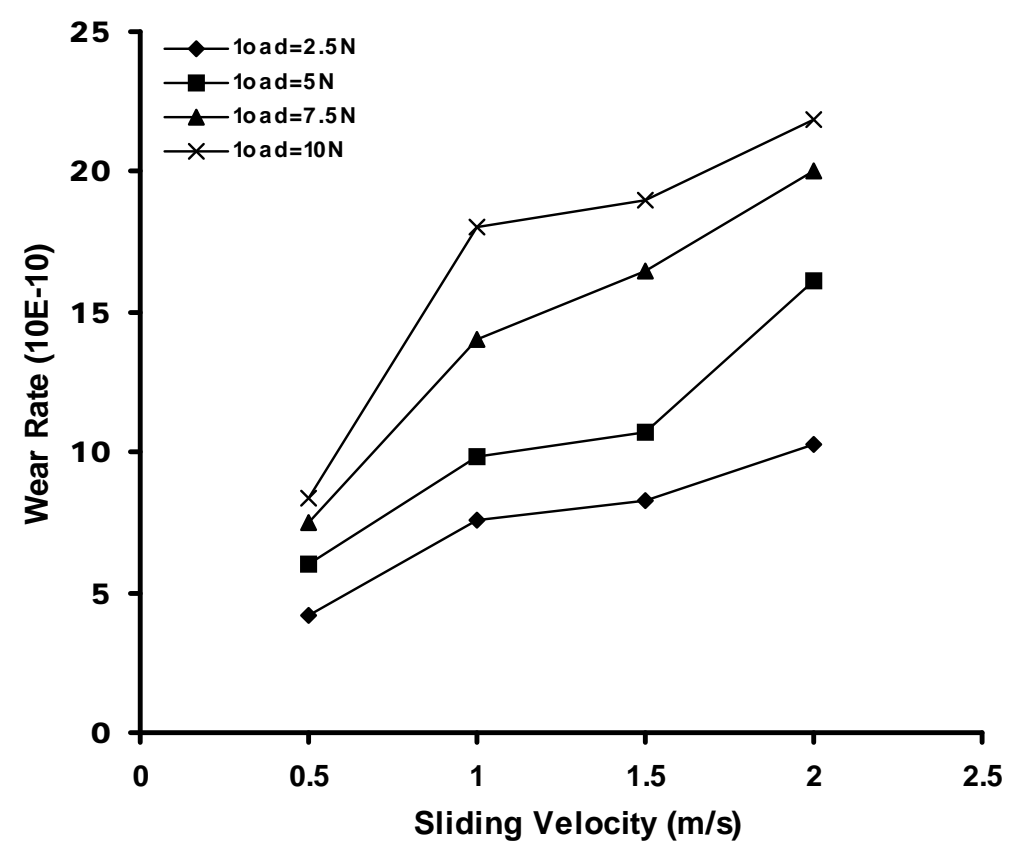

Fig. 5: Wear rate versus sliding velocity (dry sliding condition). 


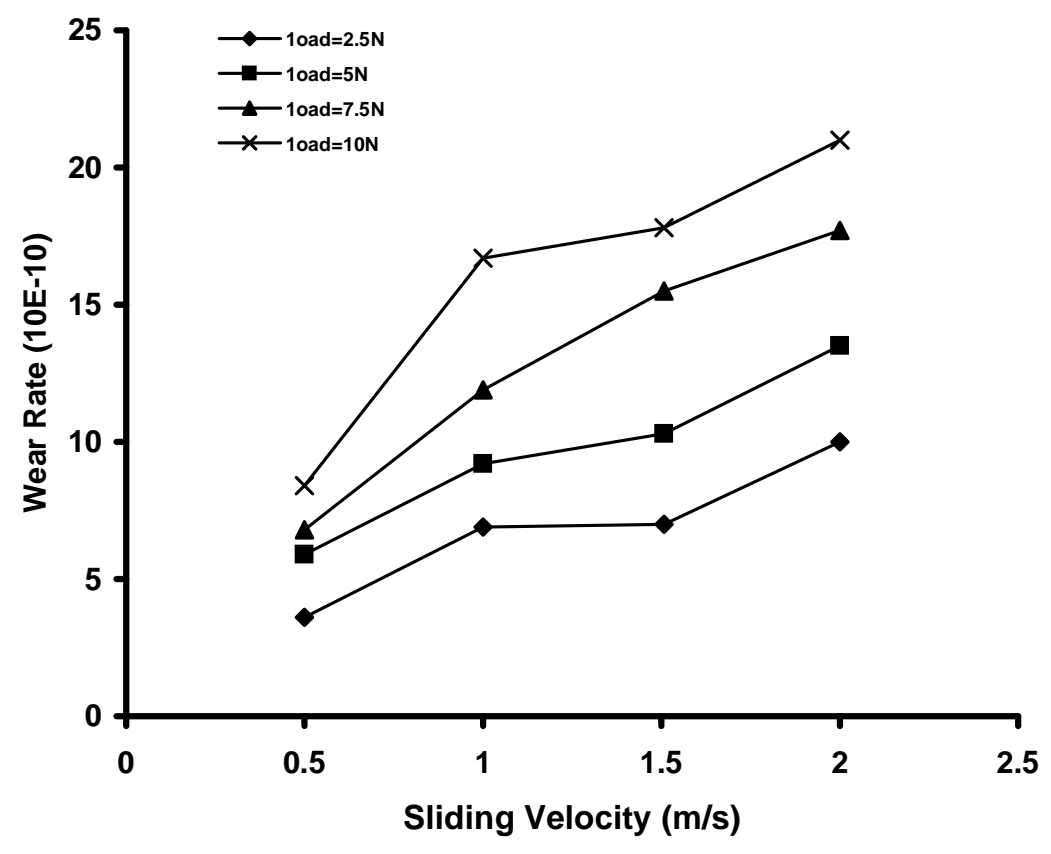

Fig. 6: Wear rate versus sliding velocity (dry with silicon carbide additive).

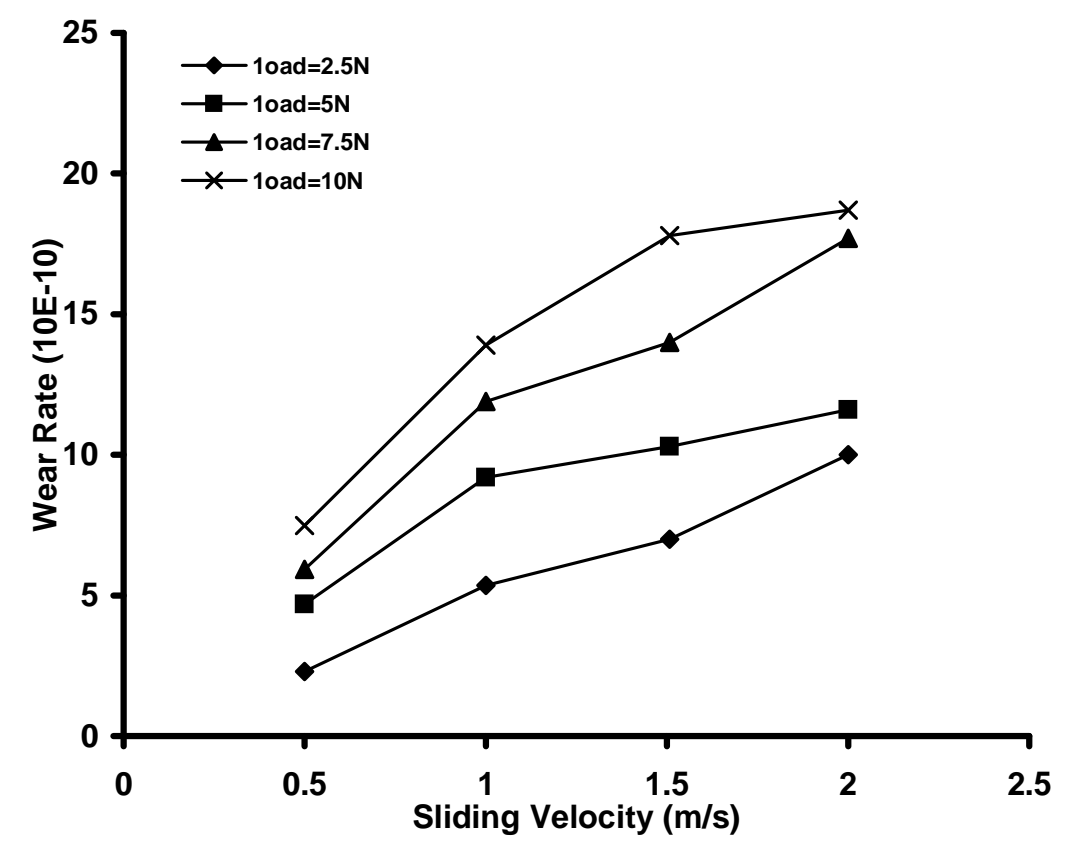

Fig. 7: Wear rate versus sliding velocity (lubricated sliding condition). 


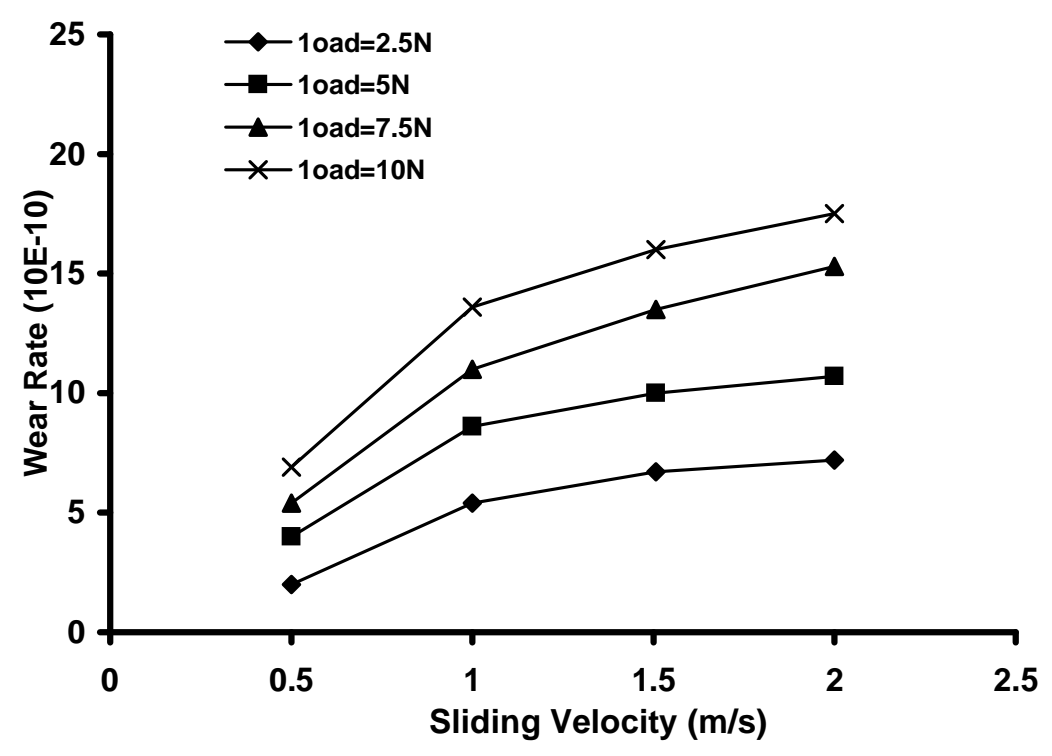

Fig. 8: Wear rate versus sliding velocity (lubricated with silicon carbide additive).

\subsection{Applied Normal Load}

The effects of applied load on the wear rate are shown Figures 9 to 12. It was found that, with increasing applied load, the wear rate increases for all these tests. This is attributed to the increase of the fiber break and debonding with increasing the applied loads.

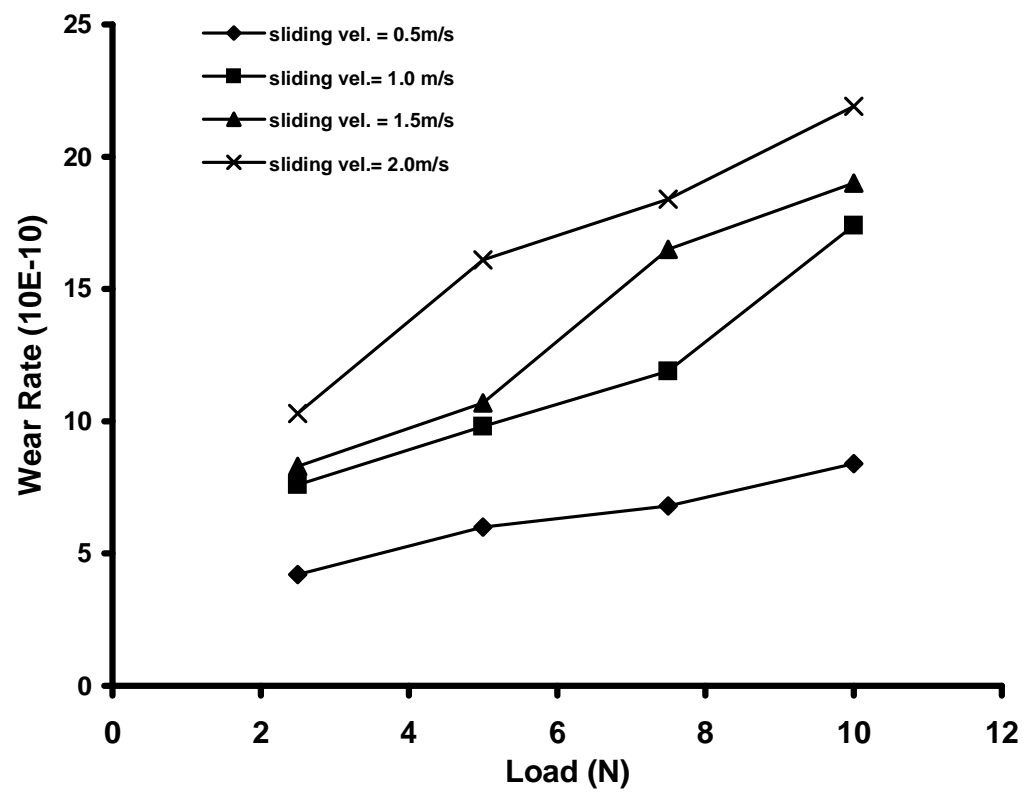

Fig. 9: Wear rate versus load (dry condition). 


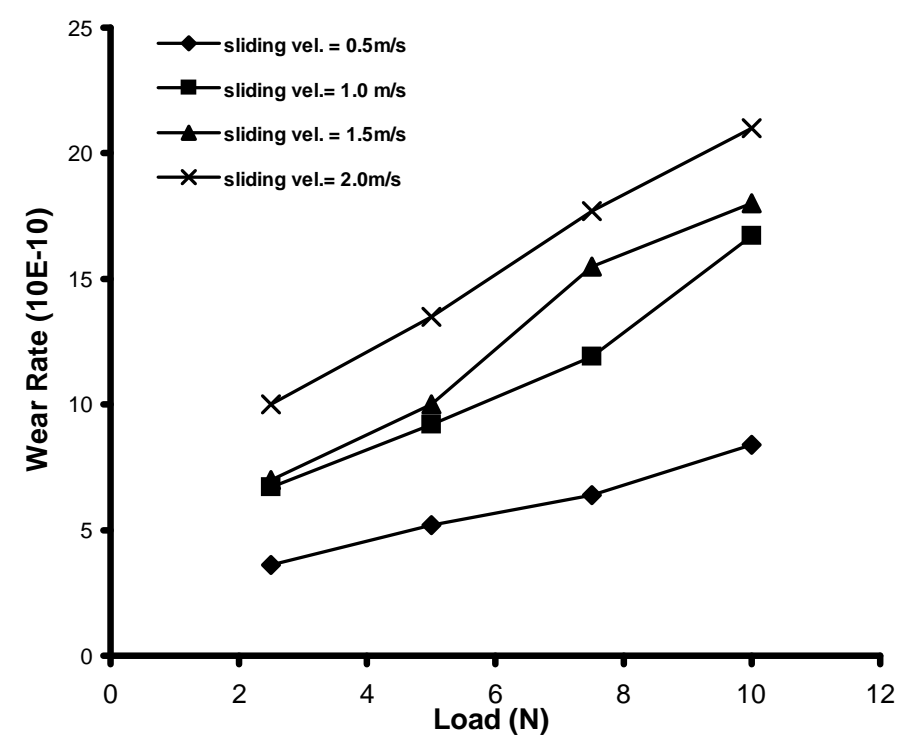

Fig. 10: Wear rate versus load (dry with additive).

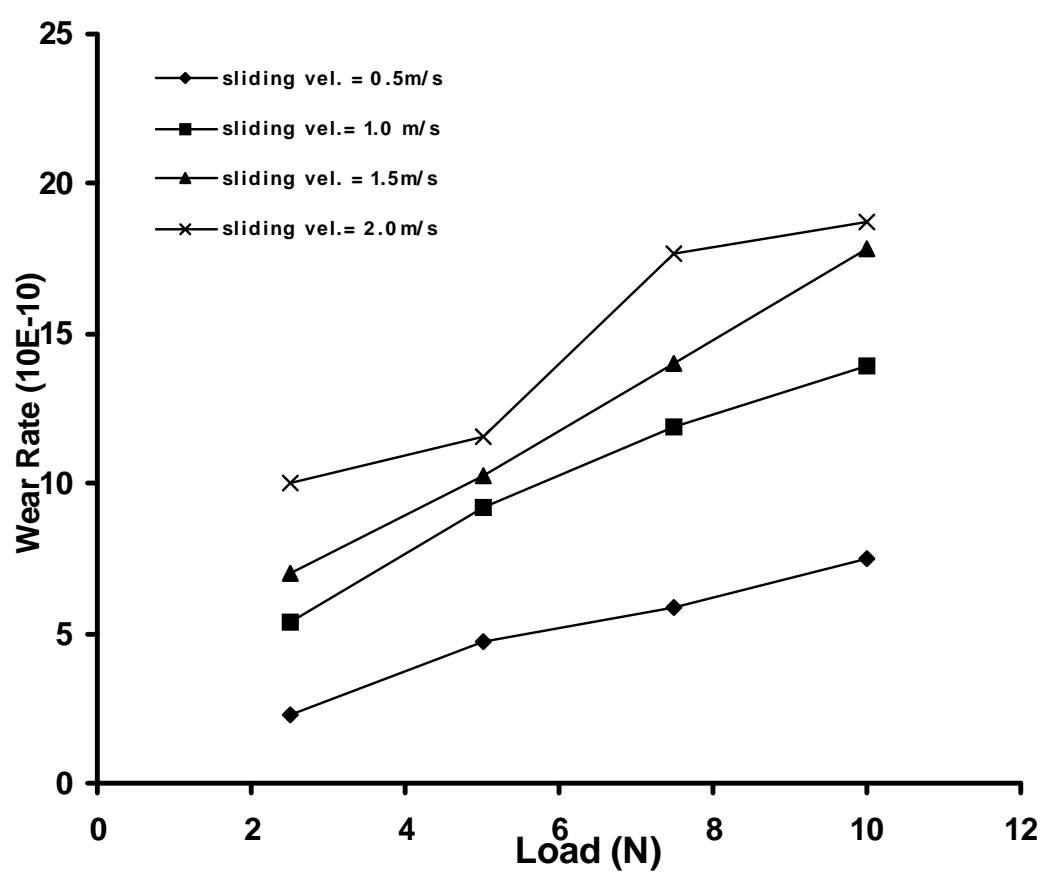

Fig. 11: Wear versus load (lubricated condition). 


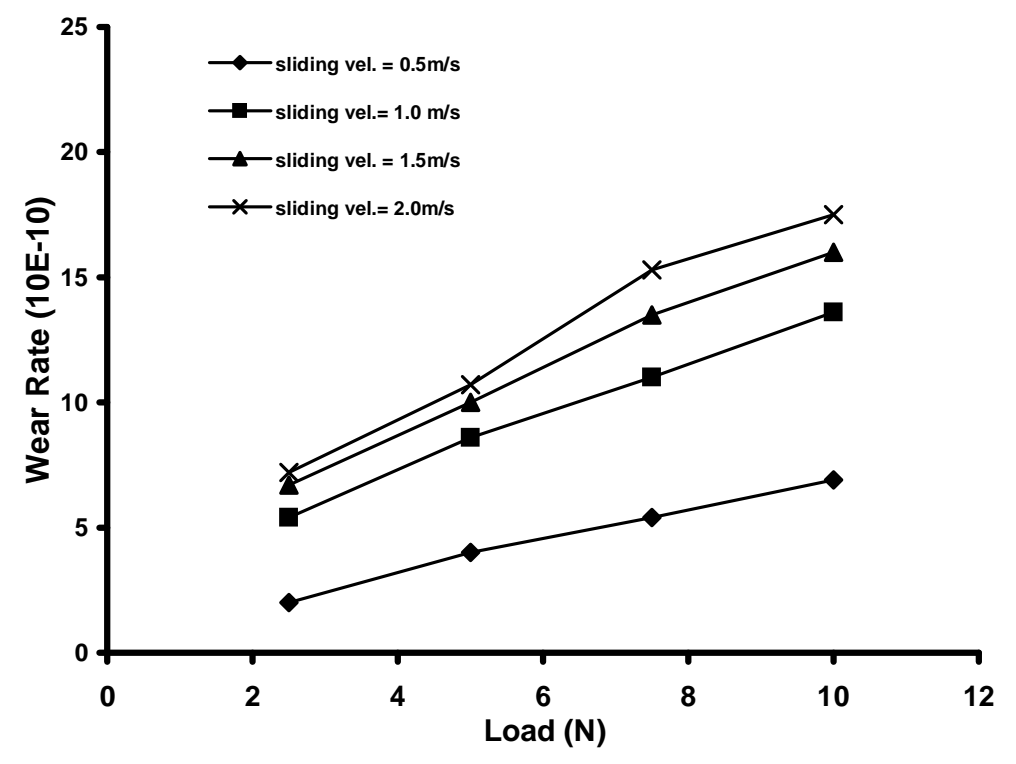

Fig. 12: Wear rate versus load (lubricated with additive).

\subsection{Wear Testing Condition Effect}

The effect of siding velocity on the wear rate at constant loads for dry, lubricated, dry with additives and lubricated with additives specimens are shown in Fig. 13. The highest wear rate of 22 E-10 was found for the composite specimens lubricated with additives. Figure 14 shows the effect of the applied normal load on wear rate at constant velocities for specimens of same types as the specimens of Fig 13.

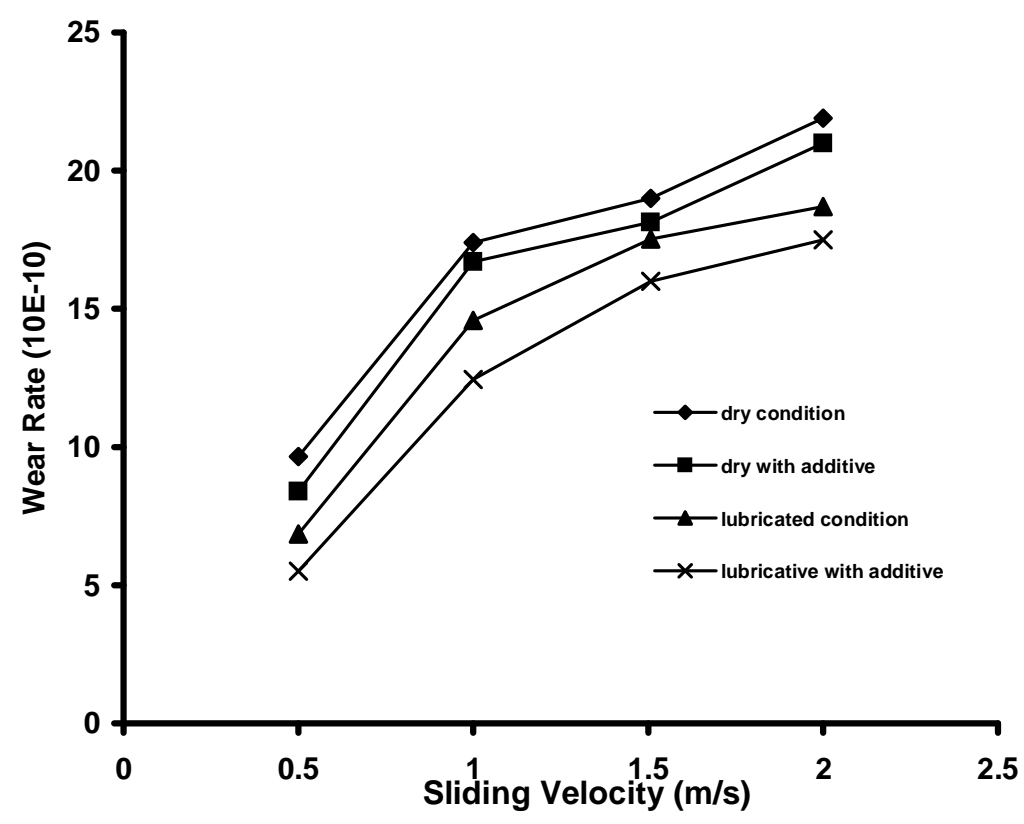

Fig. 13: Wear rate versus sliding velocity (at different conditions of sliding tests). 


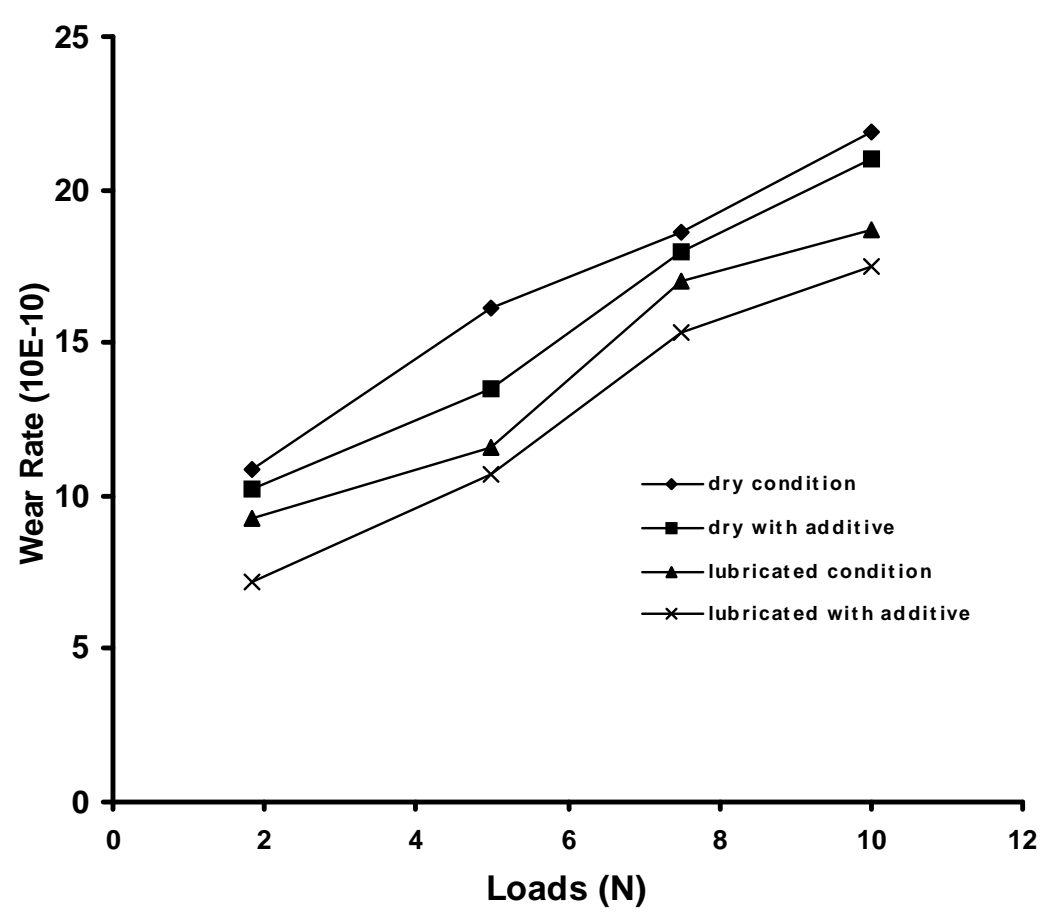

Fig. 14: Wear rate versus load (at different conditions of sliding tests).

\subsection{Scanning Electron Micrographs}

The microstructures for the worn surfaces of the woven roving aramid/epoxy composite specimens have been examined by using a scanning electron microscope (JEOL JSM6500) with magnification of 70 times. The SEM scanning electron micrographs of the worn surfaces of specimens tested at a sliding velocity of $1 \mathrm{~m} / \mathrm{s}$ and applied load of 7.5 $\mathrm{N}$ are shown in Fig.15. This figure includes four scanning electron micrographs of dry, lubricated, dry with additives and lubricated with additives specimens. Another scanning electron micrograph was taken (Fig. 16) for the sliding velocity of $2 \mathrm{~m} / \mathrm{s}$ and applied normal load of $10 \mathrm{~N}$. Specimens of dry, lubricated, dry with additives and lubricated with additives were also used. It could be seen from these micrographs that the lowest debonding and delamination was found at the worn surfaces for the composite specimens with additives and lubricant.

In general, the debonding and delamination occur on the worn surfaces at different levels. During sliding, the asperities present on the counterface surface produce lateral impacts on the exposed woven roving aramid fibers causing them to break. Lubricants decrease the debonding on fibers. The increase in debonding causes more fractures in the fibers and it will be increased as the loads increase. This may be attributed to the inherent increase in the brittleness of the aramid/epoxy specimens. Furthermore, the effect was higher in the dry and dry with additives conditions. 


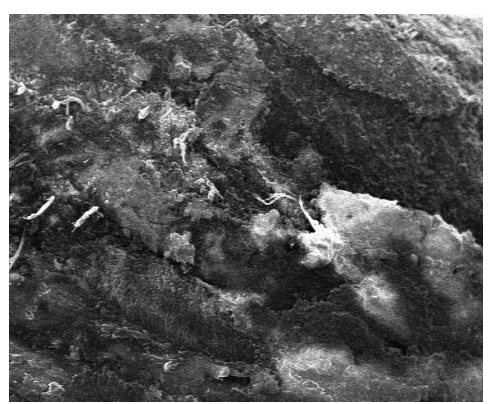

a. Dry condition without additives.

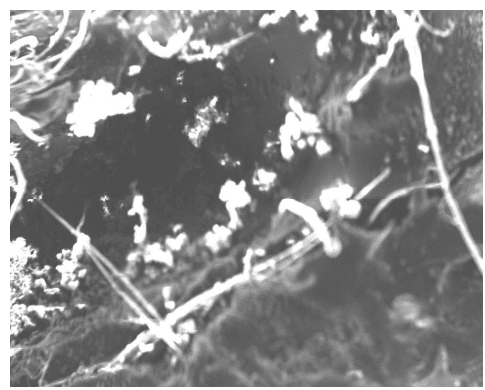

c. Lubricated condition without additives.

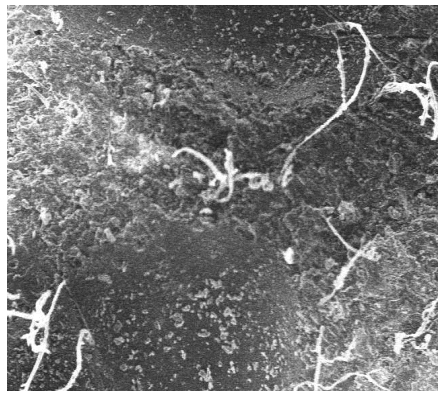

b. Dry condition with additives.

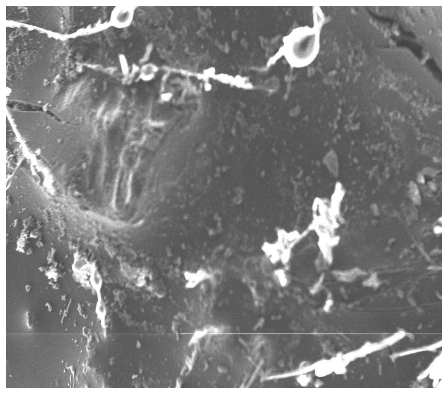

d. Lubricated condition with additives.

Fig. 15: Scanning electron micrographs for the worn surface of Woven/roving/ epoxy composite specimens at sliding speed of $1 \mathrm{~m} / \mathrm{s}$ and applied normal load of $7.5 \mathrm{~N}$.

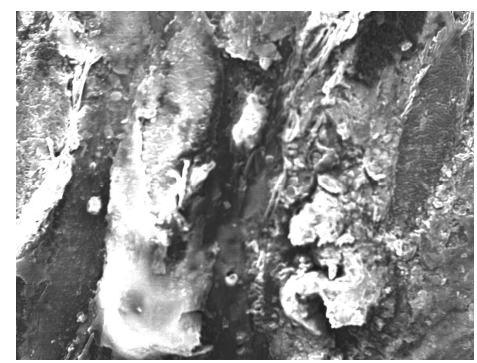

a. Dry condition without additives.

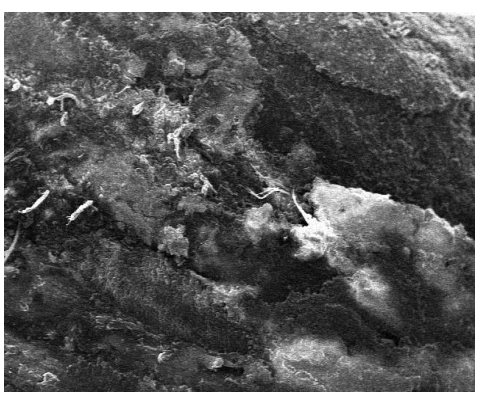

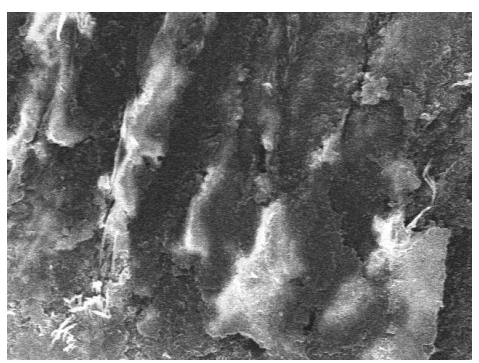

b. Dry condition with additives.

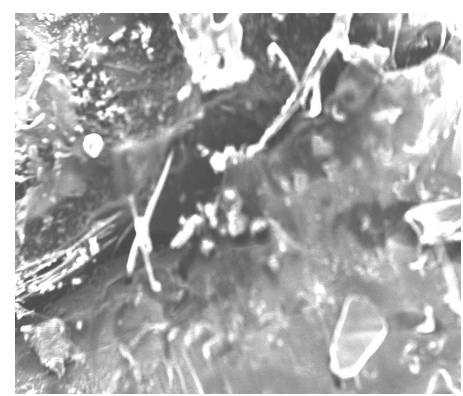

c. Lubricated condition without additives. d. Lubricated condition with additives.

Fig. 16: Scanning electron micrographs for the worn surface of woven roving/epoxy composite specimens at sliding speed of $2 \mathrm{~m} / \mathrm{s}$ and applied normal load of $10 \mathrm{~N}$. 


\section{DISCUSSION AND CONCLUSIONS}

The equipment was designed and fabricated to conduct the wear tests for the composite material used. Tests were conducted carefully for all the specimens. The average of three tests was taken for each type of composite specimens. Wear test graphs exerted from this investigation show the same trend when compared to other investigations (3) It was shown that the wear rate increased with increasing the applied load. While there is a difference in the overall wear rate for the tested conditions.

The main conclusions which can be drawn from this investigation are:

1) With increasing applied normal load, the wear rate increases for all the tested specimens. The effect of applied load was found higher for the case of dry wear tests.

2) Wear loss in lubricated tests for the same testing loads and speeds decreases and produces lower values of wear rates than other testing conditions.

3) Silicon carbide additives decrease the wear rate for woven roving aramid/epoxy composites for both the dry and lubricated wear tests.

4) Results show that the change of the applied normal load and sliding velocity has a nonlinear effect on the wear rate for the woven roving aramid composite.

5) Scanning electron micrographs show that, debonding and delamination decreases for the specimens when using the lubricant with additives at the same applied normal loads and sliding velocities.

\section{ACKNOWLEDGEMENTS}

The author would like to thank the Research Centre, International Islamic University Malaysia (IIUM) for providing financial support. Thanks are due to Mr Fadli K. and Hisham for preparing the specimens. Special thanks are also due to the Department of Mechanical Engineering, Faculty of Engineering, IIUM, for providing help for SEM microscopic analysis in the Materials and Metallurgy Lab.

\section{REFERENCES}

[1] N. H. Sung and N. P. Suh, "Effect of Fiber Orientation on Friction and Wear of Fiber Reinforced Polymeric Composites", Wear, Vol. 53, pp. 129-141, 1980.

[2] B. Vishwanath, A. P. Verma, C.V.S.K. Rao, and R. K. Gupta, "Effect of Different Matrices on Wear Characteristics of Glass Woven Roving Polymer Composites", Composites, Vol. 24, No. 4, pp. 347-353, 1993.

[3] I. C. Visconti, A. Langella and M. Durante, "The Wear Behavior of Composite Materials with Epoxy Matrix Fulled with Hard Powder" Applied Composite Materials, Vol. 8, pp. 179-189, 2001.

[4] Y. Sirong, H. Zhenming and C., Kai, "Dry Sliding Friction and Wear Behavior of Short Fiber Reinforced Zinc-Based Alloy Composites”, Wear, Vol. 198 ,pp. 108-114, 1996.

[5] B. Vishwanath, A. P. Verma, and V. S. K. Rao, "Friction and Wear of Glass Woven Roving Modified Phenol Composite", Composites, Vol.21, No. 6, pp. 531-536, 1990. 
[6] N. S. El-Tayeb and R. M. Gadelrab, "Friction and Wear Properties of E-Glass Fiber Reinforced Epoxy Composites Under Different Sliding Contact Conditions", Wear, Vol. 192, pp. 112-117, 1996.

[7] S. Bahadur and V.K. Polineni, "Tribological Studies of Glass Fabric-Reinforced Polyamide Composites Filled with CuO and PTFE", Wear, Vol. 200, pp. 95-104, 1996.

[8] M.D. Dermudez G.M. Nicolas., F.J. Carrion, I.M. Mateo., J.A. Rodriguez, and E.J. Herrera, Dry and Lubricated Wear Resistance of Mechanically Alloyed AluminumBase Sintered Composites, Wear,Vol. 248, pp. 178-186, 2001.

[9] L. Peiqing, X. Qunji and L. Weimin, 2000, Tribological Properties of $\mathrm{Ni}_{3} \mathrm{Al}_{-}-\mathrm{Cr}_{7} \mathrm{C}_{3}$ Composite Coating Under Water Lubrication", Tribology International, Vol. 33, pp.469-47

[10] L.A. Plato and M. J. Michno, Aramid Fiber in Advanced Composite. Springer - Verlag. Vol. 24, pp. 81-86, 1994.

[11] Matrinez M. A., Navarro C., Cortes R., Redriguez J., 1993. Friction and wear behavior of Kevlar Fabrics. Journal of Material Science Vol. 28, 1305-1311, 1993.

\section{BIOGRAPHY}

Dr. Asad A. Khalid is currently working as an assistant professor at the Faculty of Engineering, International Islamic University Malaysia. He obtained his B.Sc. in 1986 and M.Sc. in 1993, Mechanical Engineering Department, Faculty of Engineering, Basrah University, Iraq. He received his Ph.D. in 1999 from the Department of Mechanical Engineering, Faculty of Engineering, University Putra Malaysia, UPM, Malaysia. His area of interest is stress analysis in composite materials. 